\title{
Comparison of Efficacy of Ketoprofen and Ibuprofen in Treating Pain in Patients with Rheumatoid Arthritis: A Systematic Review and Meta-Analysis
}

\author{
Fabiola Atzeni · Ignazio F. Masala • Michela Bagnasco • \\ Luigi Lanata $\cdot$ Flavio Mantelli · Piercarlo Sarzi-Puttini
}

Received: November 27, 2020 / Accepted: February 18, 2021 / Published online: March 5, 2021

(C) The Author(s) 2021

\begin{abstract}
Introduction: Patients with rheumatoid arthritis (RA) or other rheumatic diseases say that pain and stiffness are symptoms affecting their quality of life. Ketoprofen and ibuprofen are the most commonly used non-steroidal anti-inflammatory drugs (NSAIDs) to reduce inflammation and manage mild-to-moderate pain. The aim of this new systematic review of the literature and meta-analysis of randomized controlled trials (RCTs) was to compare the clinical efficacy of ketoprofen and ibuprofen in patients with RA.

Methods: The MEDLINE and EMBASE scientific databases were systematically searched from
\end{abstract}

Supplementary Information The online version contains supplementary material available at https:// doi.org/10.1007/s40122-021-00250-3.

F. Atzeni $(\bowtie)$

Rheumatology Unit, University of Messina,

Messina, Italy

e-mail: atzenifabiola@hotmail.com

I. F. Masala

Orthopedic Unit, Santissima Trinità Hospital,

Cagliari, Italy

M. Bagnasco · L. Lanata · F. Mantelli

Medical Department, Dompé Farmaceutici S.P.A,

Milan, Italy

P. Sarzi-Puttini

Rheumatology Unit, Luigi Sacco Hospital, Milan, Italy their inception to November 2020 to identify RCTs directly comparing the recommended therapeutic doses of oral ketoprofen (50-$200 \mathrm{mg} /$ day) with ibuprofen (600-$1800 \mathrm{mg} /$ day) for RA pain relief. The metaanalysis was made using the standardized mean differences (SMD) of each of the identified RCTs using a fixed effects model.

Results: Four RCTs involving 456 patients met the inclusion criteria. The results of the metaanalysis showed a statistically significant difference in efficacy in favor of ketoprofen $(0.33$, $95 \%$ CI $0.14-0.52, p=0.0005)$ at all point-estimates of the mean-weighted size effect. The heterogeneity test for the efficacy outcome (the hypothesis was $\chi^{2}=3.57 \%, \quad d f=3$, $p$ value $=0.31$ and the chance of a test effect was $3.49, p=0.0005$ ) was not significant, and this was confirmed by a Higgins percentage of $16 \%$. The studies included in the meta-analysis did not reveal any significant differences between the two drugs in terms of tolerability or safety.

Conclusions: The result of this meta-analysis shows that ketoprofen is more effective than ibuprofen in managing RA pain at therapeutic doses, thus supporting its use in clinical practice.

Keywords: Ibuprofen; Ketoprofen; NSAIDs; Pain; Rheumatoid arthritis 


\section{Key Summary Points}

\section{Why carry out this study?}

Pain is the primary reason patients with inflammatory arthritis seek rheumatological care.

Treatment with ketoprofen and ibuprofen is the most used to reduce inflammation and manage mild-to-moderate pain.

This systematic review of the literature and meta-analysis compared the clinical efficacy and pain-relieving capacity of ketoprofen with that of ibuprofen in patients with the specific pain condition of RA.

\section{What was learned from the study?}

The results showed a statistically significant difference in efficacy in favor of ketoprofen in all point estimates of the effect of the average weighted size $(0.33$, 95\% CI $0.14-0.52 ; p=0.0005$ ), but there was no statistically significant tolerability and safety difference between the two molecules.

The efficacy and good safety profile of ketoprofen indicate that it has a better risk/benefit ratio than ibuprofen at the recommended doses, a finding that should be taken into account by clinicians when dealing with RA patients experiencing moderate-to-severe pain.

\section{DIGITAL FEATURES}

This article is published with digital features, including a summary slide, to facilitate understanding of the article. To view digital features for this article go to https://doi.org/10.6084/ m9.figshare.14046446.

\section{INTRODUCTION}

Rheumatoid arthritis (RA) is a systemic autoimmune disease characterized by inflammatory arthritis and extra-articular manifestations [1] with a high heterogeneity and therefore it can be defined as a multi-faceted inflammatory disease [2]. RA not only affects the joints and their surrounding structures but is also a systemic disease capable of involving multiple organ systems such as cardiac and pulmonary systems [3]. It is the most frequent chronic inflammatory arthritis, as it affects $0.5-1 \%$ of adults in developed countries, and is traditionally associated with a substantial burden of disease, lost working productivity, and increased mortality $[4,5]$.

Pain is the primary reason patients with inflammatory arthritis seek rheumatological care, and one of the top three priorities of $68-90 \%$ of RA patients [6], as it causes psychological distress and sleep disturbance, and may even be a greater cause of disability than structural joint damage. Pain is associated with disease activity (and radiographic changes may be related to future pain) and, together with stiffness and progressive joint damage, is caused by inflammation. However, it is becoming increasingly possible to suppress inflammation completely and ensure clinical remission, and long-term outcomes may be improved if this is rapidly achieved. The effective suppression of inflammatory disease during the first years after a diagnosis of RA tends to decrease the level of pain, although it often does not completely disappear, and may subsequently increase once again [7].

The management of mild-to-moderate pain has traditionally been based on the use of nonsteroidal anti-inflammatory drugs (NSAIDs) and the synthetic non-opioid analgesic acetaminophen, both of which are effective, widely recommended, and extensively used [8].

Ketoprofen and ibuprofen are NSAIDs belonging to the family of propionic derivatives that have been used in Europe and the USA to treat chronic painful conditions such as osteoarthritis, RA, and acute mild-to-moderate pain (e.g., primary dysmenorrhea and tension- 
type headache) for the last 30 years $[9,10]$. Ketoprofen is a racemic mixture of which only the S-isomer possesses cyclo-oxygenase inhibiting activity; the R-isomer is much less potent $[11,12]$. After oral administration, it is almost completely absorbed by the gastrointestinal tract and is highly bound (>90\%) to plasma proteins, with peak plasma concentration reached after 15 min [9].

In a previous meta-analysis [8], we demonstrated that ketoprofen was superior to ibuprofen and/or diclofenac (another widely used NSAID) in relieving various kinds of moderateto-severe pain conditions, including rheumatic disorders. In this systematic review of the literature and meta-analysis, we only focused on studies on RA because this disease has a considerably strong inflammatory component and represents one of the key osteoarticular inflammatory pathologies. The primary aim was to compare the clinical efficacy and pain relief capacity of ketoprofen with that of ibuprofen, in patients with the specific pain condition of RA, based on randomized controlled trials (RCTs) comparing the two drugs in order to guarantee homogeneity and lower the risk of bias.

Given various recent reports concerning cardiovascular, hepatic, and gastrointestinal adverse events associated with the chronic administration of NSAIDs [13-16], the major regulatory authorities have recommended administering the lowest effective doses for the shortest time necessary to control symptoms and reach therapeutic goals. Our secondary aim was therefore to evaluate the safety and tolerability of ketoprofen and ibuprofen in order to fully assess their benefit-risk profiles.

\section{METHODS}

This meta-analysis was designed and made in accordance with the Preferred Reporting Items for Systematic Reviews and Meta-Analyses (PRISMA) statement [17, 18]. This article is based on previously conducted studies and does not contain any new studies with human participants or animals performed by any of the authors.

\section{Data Sources}

The studies included in the analysis had to be RCTs evaluating the efficacy of ketoprofen and ibuprofen in treating pain in patients with RA. The systematic search of the MEDLINE and EMBASE databases from their inception to November 2020, which was also extended to grey literature sources, used the key words/ MeSH and EMTREE terms "rheumatoid arthritis" or "inflammatory arthritis" or "chronic arthritis" and "pain" or "ketoprofen" or "ibuprofen" and "inflammatory pain" or "chronic pain" combined with Boole's logical operators. The reference lists of previous reviews and the included studies were also examined, as were EULAR and ACR conference abstracts. There was no language limitation, and any papers not in English were translated.

The patients participating in the RCTs included in the meta-analysis were adults with RA treated with oral ketoprofen or ibuprofen. In order to ensure adherence to therapeutic doses and the homogeneity of the effect sizes, we only selected trials in which ketoprofen and ibuprofen were used at daily doses within their respective therapeutic ranges of 50-200 $\mathrm{mg}$ /day and $600-1800 \mathrm{mg} /$ day. These doses are in accordance with the posology recommended in clinical practice for the treatment of moderateto-severe pain. In addition, the trials had to evaluate the improvement of pain as an outcome, regardless of the assessment method used. Finally, in order to evaluate the tolerability and safety of the two drugs, we included the studies stating the number or percentage of patients experiencing adverse events and the number or percentage of withdrawn patients.

Non-randomized trials or studies that did not directly compare ketoprofen with ibuprofen, or compared ketoprofen with ibuprofen plus a narcotic or non-narcotic agent, and studies in which the drugs were not administered orally or were not administered at daily doses within their therapeutic ranges were excluded. In order to minimize heterogeneity, we also excluded retrospective studies reviews, letters, editorials, conference papers, case reports, basic science papers, and clinical practice guidelines (Table 1). 
Table 1 Criteria for including and excluding trials in the meta-analysis

$\begin{array}{ll}\text { Inclusion criteria } & \\ \text { Trial design } & \text { Randomized controlled trial } \\ \text { Study population } & \begin{array}{c}\text { Patients aged }>18 \text { years affected } \\ \text { by rheumatoid arthritis }\end{array} \\ \text { Dose } & \begin{array}{l}\text { Therapeutic doses: ketoprofen } \\ 50-200 \mathrm{mg} / \text { day and ibuprofen } \\ \text { 600-1800 mg/day }\end{array} \\ \text { 1. Efficacy meta-analysis: Visual } \\ \text { analogue scale (VAS), pain scales, } \\ \text { pain relief, responders, total } \\ \text { symptom rating score, joint } \\ \text { index, percentage of improved vs. } \\ \text { percentage of unimproved } \\ \text { patients } \\ \text { 2. Tolerability meta-analysis: } \\ \text { number or percentage of patients } \\ \text { experiencing adverse events } \\ \text { 3. For safety meta-analysis: number } \\ \text { or percentage of withdrawn } \\ \text { patients }\end{array}$

Exclusion criteria

Trial design

$$
\text { administration }
$$

Dose and route of
Guidelines [19], two authors (FA and IFM) independently selected the RCTs, with any differences between them being settled by consensus. Subsequently, they independently reviewed the titles and/or abstracts of the identified papers and reviewed the full texts of the eligible publications using a recognized method of positive inclusion; any disagreements regarding inclusion were resolved by discussions involving all of the authors.

\section{Quality Assessment and Risk of Bias}

The quality of the selected publications was assessed using Jadad's RCT assessment scale [20], which considers blinding, randomization, and patient dropouts/withdrawals. The scale scores range from 0 to 5 , with higher scores indicating less likelihood of biased results, and a score of $\geq 3$ indicating high quality.

Using the guidelines for the assessment of risk of bias in the Cochrane Handbook, the RCTs were graded by two reviewers on the basis of randomization sequence generation, allocation concealment, incomplete outcome data, selective outcome reporting, the blinding of participants and personnel, and the blinding of outcome assessments [19]. These items were considered as key domains and classified as "adequate" (low risk of bias), "inadequate" (high risk of bias), or "unclear". Studies with adequate procedures in all domains were considered to have a low risk of bias; those with inadequate procedures in one or more key domain(s) were considered to have a high risk of bias; those with unclear procedures in one or more key domain(s) were considered to have an unclear risk of bias (Fig. 1).

\section{Data Extraction and Outcome Definition}

The extracted information included the first author, year of publication, study design, Jadad quality score, the type of disease, the number of patients and controls, the type of NSAIDs and their doses, treatment duration, mean age/gender ratios, and outcome measure(s).

The efficacy data collected from all of the articles were visual analogue scale (VAS) scores,

In accordance with the a priori inclusion criteria and following the Cochrane Collaboration 


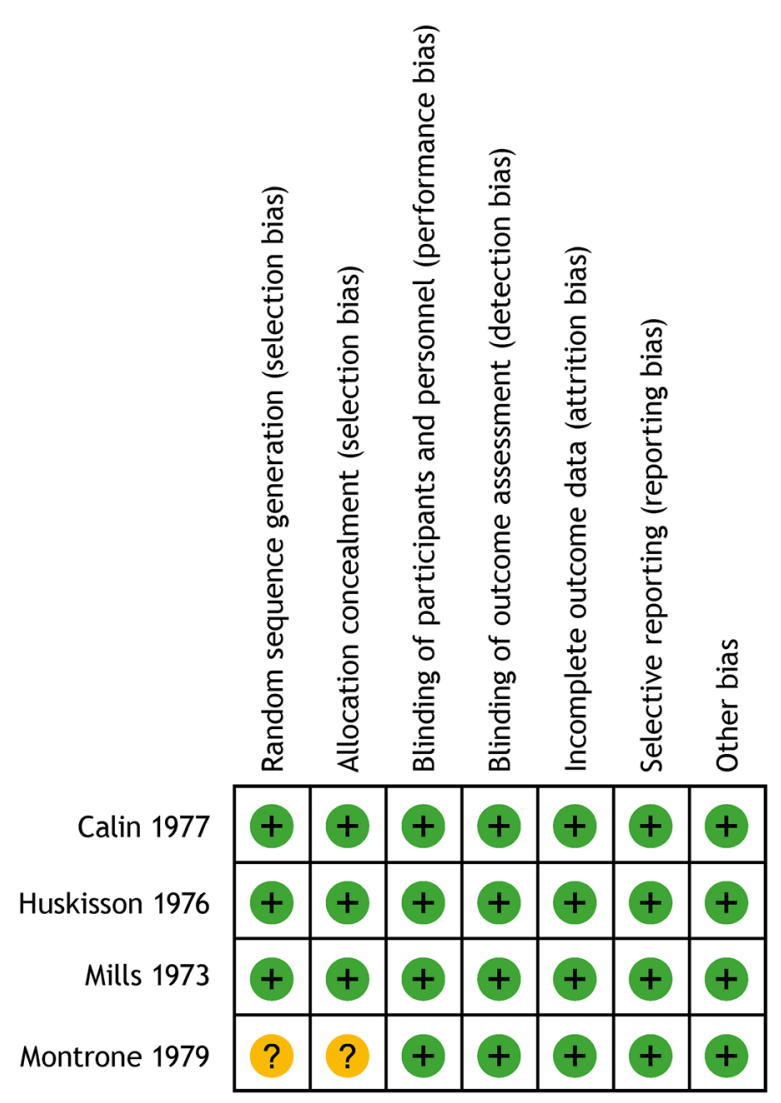

Fig. 1 Summary of each risk item of RCT

pain scale scores, pain relief scores, the number of treatment responders, total symptom rating scores, joint counts, and the percentage of improved and unimproved patients. The tolerability and safety meta-analyses were respectively made using the number or percentage of patients experiencing adverse events, and the number or percentage of withdrawn patients.

\section{Statistical Analysis}

The meta-analysis was made using the standardized mean differences (SMD) of each RCT. The mean differences (MD) and 95\% confidential intervals (CIs) of the continuous outcomes were calculated, with a fixed effects model being used because of the possible variability in population characteristics across studies. The odds ratios (ORs) of the dichotomous data collected in the individual studies were calculated, and a fixed effects meta-analysis was done to calculate the pooled estimates of effect.

Publication bias was not assessed using a funnel plot because of the limited number of studies, but heterogeneity was measured using the $I^{2}$ test with a threshold of $50 \%[19,21]$ and a sensitivity analysis was done by excluding any outliers from the final analysis. The meta-analyses were made using version 5.2.11 Review Manager software.

\section{RESULTS}

\section{Search Results}

The initial keyword and hand search yielded 411 publications, 17 of which were duplicates. Three hundred and ninety-four articles were screened based on title or abstract and 379 of them were excluded. Of the 15 full-text articles analyzed, four articles were assessed for eligibility. The meta-analyses were therefore based on the four remaining articles [22-25], all comparing ketoprofen and ibuprofen treatment in patients with RA. Figure 2 shows a flowchart of the selection process.

\section{Characteristics of the Studies Included in the Meta-Analysis}

Table 2 shows the characteristics of the four RCTs included in the meta-analysis. They involved a total of 456 patients (229 treated with ketoprofen and 227 treated with ibuprofen), and three had a cross-over design $[22,23,25]$.

There were no major differences in the characteristics of the patients in the four RCTs. The mean age was 55 years with a higher percentage of females (62\%) than males (38\%) and with a duration of illness of $1-5$ years or $>5$ years in most cases. They all had classic or definite RA as defined by the American Rheumatism Association and were indicated for treatment. The patients in three of the trials [22-24] were untreated with corticosteroids or immunosuppressive drugs for periods ranging from 1 day to 3 months. Simple analgesics were 


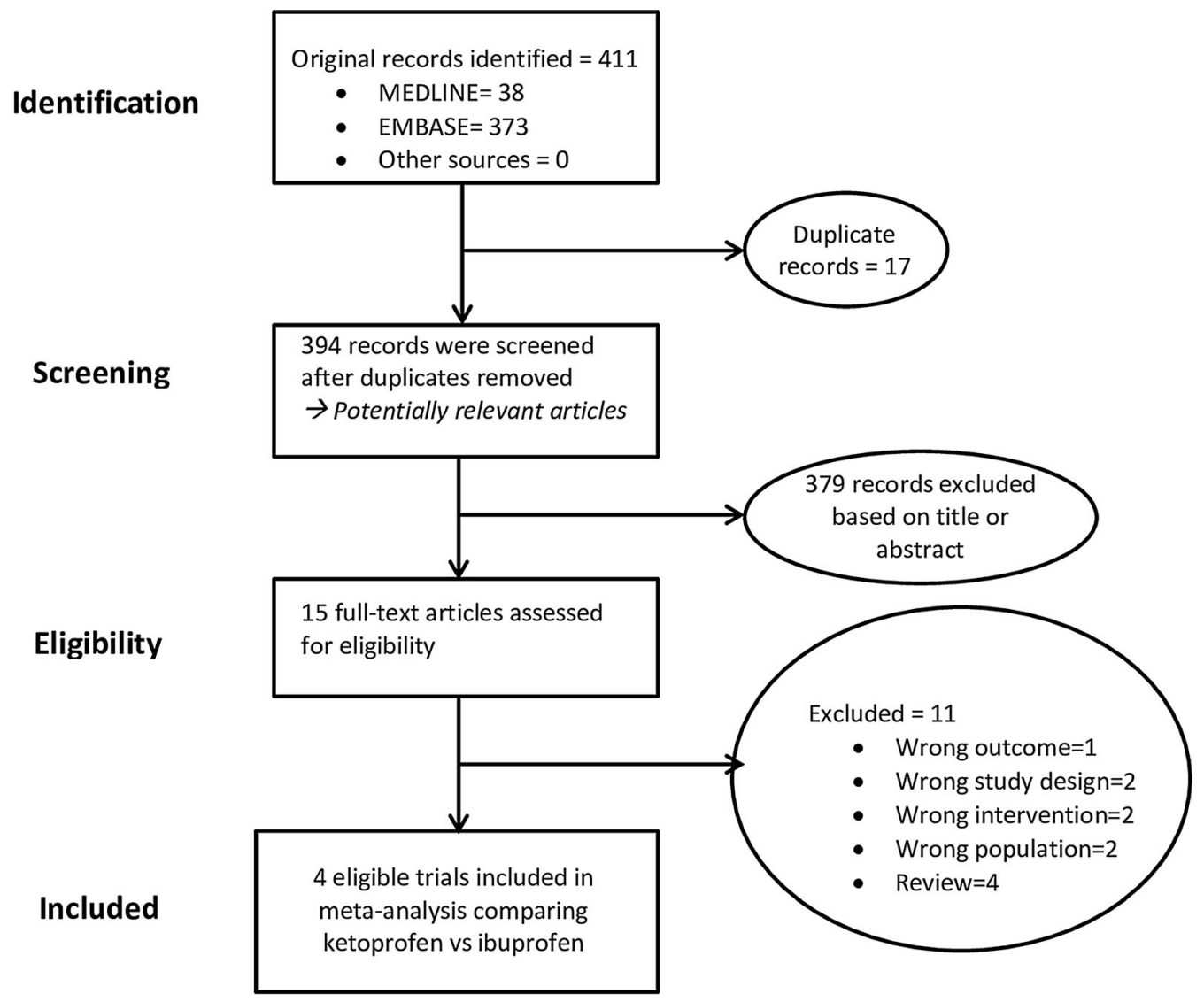

Fig. 2 Flowchart of the selection process for studies included in the meta-analysis

only allowed during Huskisson's study [25], and 16 patients already being treated with small doses of corticosteroids continued taking them.

The ketoprofen and ibuprofen doses assessed in the studies were $150-300$ and 1200-$1800 \mathrm{mg} /$ day, respectively; treatment duration ranged from 10 days to 3 months.

All of the studies considered changes in pain as evaluated by VAS or point scores. Two studies of 142 patients treated with ketoprofen and 140 treated with ibuprofen $[24,25]$ included duration of stiffness scores, and two studies of 86 patients treated with ketoprofen and 84 treated with ibuprofen $[22,23]$ included grip strength scores.

Adverse events and withdrawal rates were available for three studies with 139 patients treated with ketoprofen and 137 treated with ibuprofen [22-24]. All four RCTs [22-25] had a Jadad quality scores of $\geq 3$.

\section{Meta-Analysis of the Efficacy of Ketoprofen and Ibuprofen}

Figure 3 shows the size effect of the two drugs. The meta-analysis revealed a statistically significant difference in efficacy in favor of ketoprofen at all of the point-estimates of the mean weighted size effect $(0.33,95 \%$ CI $0.14-0.52$; $p=0.0005$ ).

The test of heterogeneity for the efficacy outcome (the hypothesis test was $\chi^{2}=3.57 \%$, $d f=3, p$ value $=0.31$ and the chance of a test effect was $3.49, p=0.0005$ ) was not significant, and this was confirmed by the Higgins percentage of $16 \%$.

The graph shows the significant distance between the "no difference" middle ordinate and the standard difference in favor of ketoprofen. 
Table 2 Characteristics of the RCTs comparing ketoprofen with ibuprofen

\begin{tabular}{|c|c|c|c|c|c|c|c|c|}
\hline $\begin{array}{l}\text { Author, } \\
\text { year }\end{array}$ & Trial design & $\begin{array}{l}\text { Jadad } \\
\text { score }\end{array}$ & $\begin{array}{l}\text { Treatment group } \\
\text { dose/day }\end{array}$ & $\begin{array}{l}\text { Treatment } \\
\text { duration }\end{array}$ & $\begin{array}{l}\text { No. of } \\
\text { patients }\end{array}$ & $\begin{array}{l}\text { Males/ } \\
\text { females }\end{array}$ & $\begin{array}{l}\text { Outcome } \\
\text { measures used } \\
\text { for meta- } \\
\text { analyses }\end{array}$ & $\begin{array}{l}\text { Overall } \\
\text { side- } \\
\text { effects } \\
\text { difference }\end{array}$ \\
\hline Calin, 1977 & $\begin{array}{l}\text { Randomized, } \\
\text { double- } \\
\text { blind, } \\
\text { parallel } \\
\text { group }\end{array}$ & 4 & $\begin{array}{l}\text { Ketoprofen } \\
\quad(150-300 \mathrm{mg}) \\
\text { Ibuprofen } \\
\quad(1200-2400 \mathrm{mg})\end{array}$ & 3 months & $\begin{array}{l}52 \\
50\end{array}$ & $\begin{array}{l}23 / 29 \\
22 / 28\end{array}$ & Joint Index & ns \\
\hline $\begin{array}{l}\text { Huskisson, } \\
1976\end{array}$ & $\begin{array}{l}\text { Randomized, } \\
\text { double- } \\
\text { blind, } \\
\text { crossover }\end{array}$ & 4 & $\begin{array}{l}\text { Ketoprofen } \\
\quad(150 \mathrm{mg}) \\
\text { Ibuprofen } \\
\quad(1200 \mathrm{mg}) \\
\text { Fenoprofen } \\
(2400 \mathrm{mg}) \\
\text { Naproxen } \\
\text { (500 mg) }\end{array}$ & 2 weeks & $\begin{array}{l}90 \\
90 \\
90 \\
90\end{array}$ & nd & Pain Score & $\mathrm{ns}$ \\
\hline Mills, 1973 & $\begin{array}{l}\text { Randomized, } \\
\text { double- } \\
\text { blind, } \\
\text { crossover }\end{array}$ & 4 & $\begin{array}{l}\text { Ketoprofen } \\
\quad(150 \mathrm{mg}) \\
\text { Ibuprofen } \\
\quad(1200 \mathrm{mg})\end{array}$ & 2 weeks & $\begin{array}{l}34 \\
34\end{array}$ & $12 / 22$ & Pain Index & $\mathrm{ns}$ \\
\hline $\begin{array}{l}\text { Montrone, } \\
1979\end{array}$ & $\begin{array}{c}\text { Double-blind, } \\
\text { crossover }\end{array}$ & 3 & $\begin{array}{l}\text { Ketoprofen } \\
\quad(200 \mathrm{mg}) \\
\text { Ibuprofen } \\
\quad(1200 \mathrm{mg})\end{array}$ & 10 days & $\begin{array}{l}53 \\
53\end{array}$ & $15 / 40$ & $\begin{array}{l}\text { Pain on } \\
\text { pressure }\end{array}$ & $\mathrm{ns}$ \\
\hline
\end{tabular}

nd not defined, $n s$ not significant

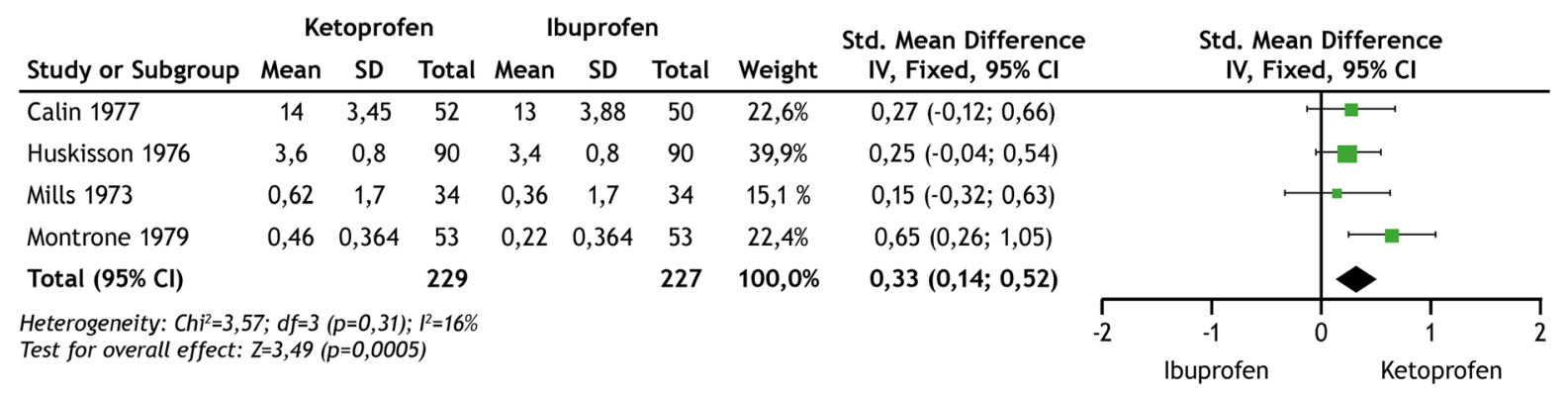

Fig. 3 Size effect of ketoprofen and ibuprofen 


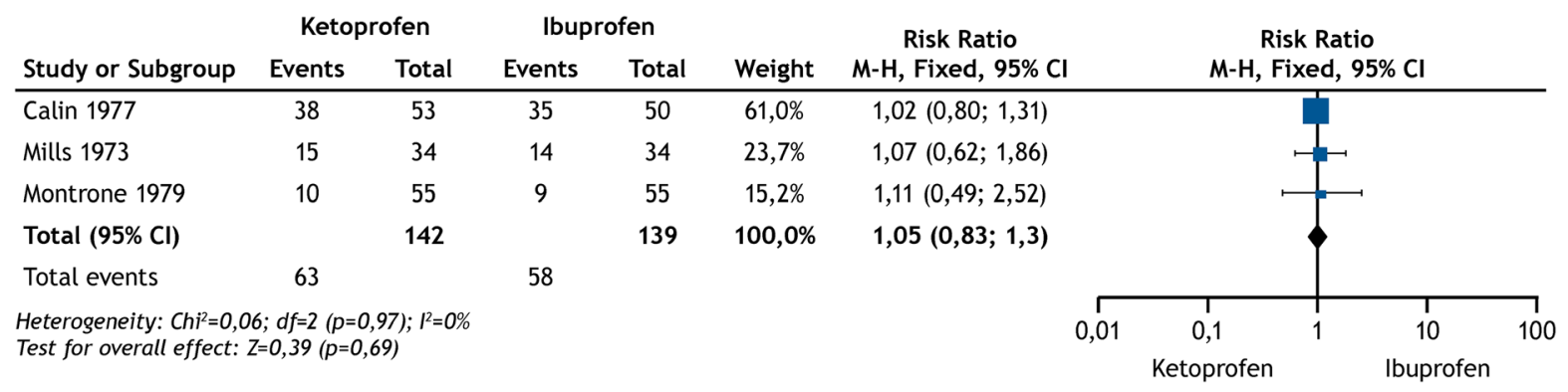

Fig. 4 Tolerability: risk ratio (RR) between ketoprofen and ibuprofen

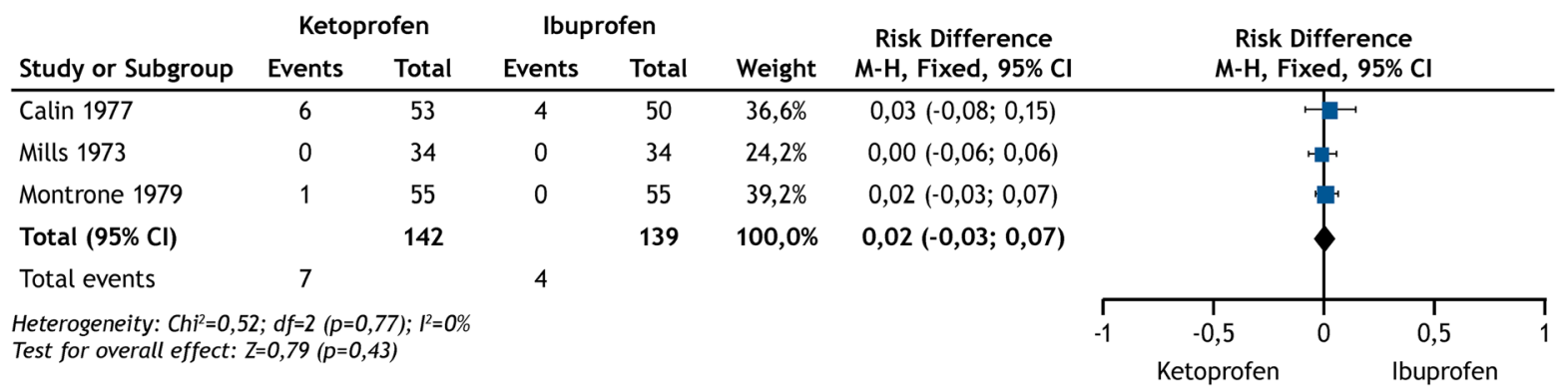

Fig. 5 Safety: risk difference (RD) between ketoprofen and ibuprofen

\section{Meta-Analyses of the Tolerability and Safety of Ketoprofen and Ibuprofen}

The analysis of tolerability (Fig. 4) evaluated the risk ratio (RR) between ketoprofen and ibuprofen $(\mathrm{RR}=1.05 ;[-0.83,1.33] \mathrm{M}-\mathrm{H}$, fixed, 95\% CI). The hypothesis test was $\chi^{2}=0.06(d f=2$; $p=0.97$ ), and $I^{2}$ was $0 \%$ [17]. There was therefore no statistically significant difference between the two molecules.

Safety was evaluated by analyzing the risk difference (RD) between ketoprofen and ibuprofen (Fig. 5). The total RD was 0.02 [-0.03, 0.7], with 7 vs. 4 events in 142 vs. 139 patients. The heterogeneity was not significant: $\chi^{2}=0.52(d f=2 ; p=0.77)$ and $I^{2}=0 \%$.

\section{DISCUSSION}

Rheumatoid arthritis is a progressive inflammatory disease that mainly affects the peripheral joints and often causes the destruction of cartilage and bone. NSAIDs represent an important pharmacologic choice in the management of inflammatory pain and they are: analgesic, antipyretic, anti-inflammatory, and platelet aggregation inhibitors. Each activity is mediated by the same mechanism of action: they block prostaglandin production by inhibiting both forms of cyclooxygenase (COX), COX1 and COX2, which are essential for the synthesis of prostaglandins.

This class of drugs includes many compounds with clinically relevant differences regarding efficacy and safety. Among the many NSAIDs available, ibuprofen, diclofenac, and ketoprofen remain the most frequently used [26].

The principal guidelines for the long-term management of RA state that symptomatic RA patients should be treated with NSAIDs (together with a proton pump inhibitor if necessary) because they have an immediate effect on pain and stiffness even if they do not influence the disease process.

The multiplicity of the currently available NSAIDs therefore provides a strong rationale for comparing their benefit-risk ratios in order to help physicians make rational therapeutic choices for managing pain. Analgesics are used to manage pain in all stages of the disease, often 
in combination with other drugs aimed at controlling inflammation but, although acetaminophen is readily available, there is little RCT-based evidence supporting its use [27-30], and trials have often used it in combination with another analgesic of a different class.

Substantial evidence, including a Cochrane review, indicates that both the non-selective and COX-2 selective NSAIDs are more effective than simple analgesics in relieving signs and symptoms of active disease in established RA. Among these drugs, we chose to compare the efficacy of ketoprofen and ibuprofen in terms of what seem to be the most clinically relevant outcomes and because they are widely prescribed to treat pain in RA patients. It is important to consider that pain, especially in this disease, is strongly correlated with the inflammatory conditions.

Ketoprofen lysine salt (KLS) has been extensively demonstrated to be very powerful in controlling the inflammatory pattern in the RA patients and thanks to its high level of liposolubility [31] it is rapidly and readily distributed into the central nervous system passing the blood-brain barrier within $15 \mathrm{~min}$, thus inhibiting the prostaglandin synthesis at the central level and into the joint space [9]. Moreover, in patients with RA, ketoprofen lysine salt demonstrated to significantly improve tenderness and to decrease the synovial prostaglandin 2 (PGE-2) levels better than naproxen after 1 week of treatment [32].

The results showed that the effect of therapeutic doses of ketoprofen was much greater than that of therapeutic doses of ibuprofen. There was no heterogeneity in the efficacy outcomes evaluated in the different studies, thus guaranteeing the reliability and validity of the results of the meta-analysis, which indicate that ketoprofen leads to a statistically significant greater improvement in the disease.

Moreover, it is important to point out that the studies included in this meta-analysis are mostly of short duration. This, however, should not be considered as a limitation. In fact, the main goal of RA management should be the prevention and control of the flares that characterize the disease. The symptomatic treatment of RA with NSAIDs focuses on the decrease of the inflammatory status and on associated damage prevention. It is generally well established that this is reached and visible already after short treatments.

Although we are aware that it is very important to select treatments on the basis of their benefit-risk ratios, particularly in the case of anti-inflammatory agents, we specifically evaluated the efficacy of the therapeutic doses recommended in clinical practice. However, we also clinically analyzed the drugs' safety profiles and found that ketoprofen and ibuprofen seem to be equally well tolerated and lead to comparably non-serious adverse reactions.

The efficacy and good safety profile of ketoprofen indicate that it has a better benefit-risk ratio than ibuprofen at the recommended doses, a finding that should be taken into account by clinicians when dealing with RA patients experiencing moderate-to-severe pain.

The efficacy results of the two analyzed drugs are confirmed in more recent papers, demonstrating that, even if dated studies were included, the outcomes regarding ketoprofen and ibuprofen in RA are still relevant and up-todate.

Finally, it is well known that the epidemiology of RA is more common in women than men (3:1). The increased risk of RA in females has led to considerable effort in examining the role of hormonal and pregnancy factors in disease occurrence and interestingly exogenous hormonal influences are implicated in disease risk. However, to date, the comprehensive knowledge of the link between sex and RA is still partially lacking $[33,34]$.

\section{Study Limitations}

All of the trials included in the analysis had methodological limitations, including unclear or inadequate allocation concealment and the absence of intention-to-treat (ITT) analyses.

Although it is true that they had different treatment durations and considered different efficacy parameters, the majority analyzed pain outcomes. In order to limit the risk of publication bias, we did not limit the year of publication but decided to include all of the available 
trials in order to increase the validity of the analysis. The small number of studies (which can be considered another limitation) is due to fact that only a few head-to-head comparative trials have been published, and further direct comparisons would be welcome in order to confirm our findings.

The strengths of the meta-analysis mainly arise from the power and homogeneity of the statistical results, and the fact that this is the first systematic analysis of all of the studies directly comparing the two NSAIDs that are the most widely used in clinical practice throughout the world. Only in the last years has the importance of gender in promoting an autoimmune dysfunction been recognized [34] such as RA. For this reason, since the studies included in the present meta-analysis were performed many years ago, they do not delve into this topic.

\section{CONCLUSIONS}

The results of this meta-analysis show that therapeutic doses of ketoprofen are more efficacious than those of ibuprofen in managing RA-related pain, thus supporting its use in clinical practice. The strong evidence on the efficacy outcome, accordingly to an overall good safety profile, underlines a better benefit-risk ratio for ketoprofen at the recommended posology that should be taken into account by clinicians when dealing with patients affected by RA with moderate-to-severe pain.

\section{ACKNOWLEDGEMENTS}

Funding. This study was supported by an unrestricted grant from Dompé Farmaceutici S.p.A, Milan, Italy. Dompé Farmaceutici S.p.A, Milan, Italy did not have any role in the study design, literature search, data collection, data analysis or data interpretation. The journal's Rapid Service Fee was funded by Dompé Farmaceutici S.p.A, Milan, Italy.
Authorship. All named authors meet the International Committee of Medical Journal Editors (ICMJE) criteria for authorship of this manuscript, take responsibility for the integrity of the work as a whole, and have given final approval for the version to be published.

Disclosures. Fabiola Atzeni, Ignazio F. Masala, Michela Bagnasco, Luigi Lanata, Flavio Mantelli, Piercarlo Sarzi-Puttini have nothing to disclose.

Compliance with Ethics Guidelines. This article is based on previously conducted studies and does not contain any new studies with human participants or animals performed by any of the authors.

Data Availability. The data sets generated and/or analyzed during the current study are available from the corresponding author on reasonable request.

Open Access. This article is licensed under a Creative Commons Attribution-NonCommercial 4.0 International License, which permits any non-commercial use, sharing, adaptation, distribution and reproduction in any medium or format, as long as you give appropriate credit to the original author(s) and the source, provide a link to the Creative Commons licence, and indicate if changes were made. The images or other third party material in this article are included in the article's Creative Commons licence, unless indicated otherwise in a credit line to the material. If material is not included in the article's Creative Commons licence and your intended use is not permitted by statutory regulation or exceeds the permitted use, you will need to obtain permission directly from the copyright holder. To view a copy of this licence, visit http://creativecommons.org/licenses/by$\mathrm{nc} / 4.0 /$.

\section{REFERENCES}

1. Chauhan K, Jandu JS, Goyal A, Bansal P, Al-Dhahi MA. Rheumatoid arthritis. In: StatPearls [Internet]. Treasure Island, FL: StatPearls Publishing; 2021. 
2. Marsal S, Julià A. Rheumatoid arthritis pharmacogenomics. Pharmacogenomics. 2010;11(5): 617-9.

3. Wasserman AM. Diagnosis and management of rheumatoid arthritis. Am Fam Physician. 2011;84(11):1245-52.

4. Mjaavatten MD, Bykerk VP. Early rheumatoid arthritis: the performance of the 2010 ACR/EULAR criteria for diagnosing RA. Best Pract Res Clin Rheumatol. 2013;27:451-66.

5. Ruyssen-Witrand A, Constantin A, CambonThomsen A, Thomsen M. New insights into the genetics of immune responses in rheumatoid arthritis. Tissue Antigens. 2012;80:105-18.

6. Lee Y. Effect and treatment of chronic pain in inflammatory arthritis. Curr Rheumatol Rep. 2013;15(1):300. https://doi.org/10.1007/s11926012-0300-4.

7. Sarzi-Puttini P, Salaffi F, Di Franco M, et al. Pain in rheumatoid arthritis: a critical review. Reumatismo. 2014;66:18-27.

8. Sarzi-Puttini P, Atzeni F, Lanata L, Bagnasco M. Efficacy of ketoprofen vs ibuprofen and diclofenac: a systematic review of the literature and metaanalysis. Clin Exp Rheumatol. 2013;31:731-8.

9. Sarzi-Puttini P, Atzeni F, Lanata L, et al. Pain and ketoprofen: what is its role in clinical practice? Reumatismo. 2010;62(172-88):2.

10. Moore N. Forty years of ibuprofen use. Int J Clin Pract. 2003;135(Suppl):28-31.

11. Barbanoj M, Antonijoan R, Gich I. Clinical pharmacokinetics of dexketoprofen. Clin Pharmacokinet. 2001;40:245.

12. Cabré F, Fernández MF, Calvo L, Ferrer X, García ML, Mauleón D. Analgesic, antiinflammatory, and antipyretic effects of S (+)-ketoprofen in vivo. J Clin Pharmacol. 1998;38:3S-10S.

13. Final Report Summary-SOS (Safety of non-steroidal anti-inflammatory drugs). SOS project. [Internet]. ROTTERDAM (Netherlands). 2013. http:// cordis.europa.eu/result/rcn/54210_it.html.

14. Gulmez SE, Larrey D, Pageaux GP, et al. Transplantation for acute liver failure in patients exposed to NSAIDs or paracetamol (acetaminophen). Drug Saf. 2013;36:135-44.

15. Arfè A, Scotti L, Varas-Lorenzo C, et al. Safety of Non-steroidal Anti-inflammatory Drugs (SOS) Project Consortium. Non-steroidal anti-inflammatory drugs and risk of heart failure in four European countries: nested case-control study. BMJ. 2016;354:i4857.

16. Masclee GMC, Straatman H, Arfè A, et al. Risk of acute myocardial infarction during use of individual NSAIDs: a nested case-control study from the SOS project. PLOS ONE. 2018;13(11):e0204746.

17. Moher D, Liberati A, Teztlaff J, Altman G, PRISMA GROUP. Preferred reporting items for systematic reviews and meta-analyses: the PRISMA statement. Ann Int Med. 2009;51:1-7.

18. Chiu YH, Chang KV, Chen IJ, Wu WT, Özçakar L. Utility of sonoelastography for the evaluation of rotator cuff tendon and pertinent disorders: a systematic review and meta-analysis. Eur Radiol. 2020;30(12):6663-72.

19. Higgins JPT, Green S. Cochrane handbook for systematic reviews of interventions. https://www. cochrane-handbook.org. Accessed 20 Mar 2011.

20. Jadad AR, Moore RA, Carroll D, et al. Assessing the quality of reports of randomized clinical trials: is blinding necessary? Control Clin Trials. 1996;17: $1-12$.

21. Higgins JP, Thompson SG, Deeks JJ, Altman DG. Measuring inconsistency in meta-analyses. BMJ. 2003;327:557-60.

22. Montrone F, Fumagalli M, Pellegrini $\mathrm{P}$, et al. A double-blind cross-over evaluation of ketoprofen (Orudis) and ibuprofen in the management of rheumatoid arthritis. Rheumatol Rehabil. 1979;18: $114-8$.

23. Mills SB, Bloch M, Bruckner FE. Double-blind crossover study of ketoprofen and ibuprofen in management of rheumatoid arthritis. Br Med J. 1973;4: $82-4$.

24. Calin A, BennetT RM, Sukhupunyaraksa S, et al. Double-blind, multi-centre parallel trial of ketoprofen and ibuprofen in the treatment of rheumatoid arthritis. Rheumatol. 1977;4:2.

25. Huskisson EC, Woolf DL, Balme HW, ScotT J, Franklin S. Four new anti-inflammatory drugs: responses and variations. Br Med J. 1976;1:1048-9.

26. Varrassi G, Alon E. Towards an effective and safe treatment of inflammatory pain: a Delphi-guided expert consensus. Adv Ther. 2019;36(10):2618-37.

27. Wienecke T, Gotzsche PC. Paracetamol vs nonsteroidal anti-inflammatory drugs for rheumatoid arthritis. Cochrane Database Syst Rev. 2004;1: CD003789. 
28. Seideman P, Melander A. Equianalgesic effects of paracetamol and indomethacin in rheumatoid arthritis. Br J Rheumatol. 1988;27:117-22.

29. Marks JL, Colebatch AN, Buchbinder R, Edwards CJ. Pain management for rheumatoid arthritis and cardiovascular or renal comorbidity. Cochrane Database Syst Rev. 2011;10:dCD08952.

30. Seideman P. Additive effect of combined naproxen and paracetamol in rheumatoid arthritis. $\mathrm{Br} \mathrm{J}$ Rheumatol. 1993;32:1077.

31. Kokki H, Karvinen M, Jekunen A. Diffusion of ketoprofen into the cerebrospinal fluid of young children. Paediatr Anaesth. 2002;12:313-6.
32. Carrabba M, Chevallard M, Mele G, Borsa M, Malandrino S, Tonon GC. Ketoprofen lysine in rheumatoid arthritis: efficacy and tolerability of two therapeutic schedules with evaluation of synovial prostaglandin levels. Current Ther Res. 1987;42:70-6.

33. Silman A, Pearson JE. Epidemiology and genetics of rheumatoid arthritis. Arthritis Res. 2002;4(suppl 3): S265-72.

34. Favalli EG, Biggioggero M, Crotti C, Becciolini A, Raimondo MG, Meroni PL. Sex and management of rheumatoid arthritis. Clin Rev Allergy Immunol. 2019;56(3):333-45. 